\title{
Assessment of the Water Pond Cooling Effect on Urban Microclimate: A Parametric Study with Numerical Modeling
}

\author{
Nedyomukti Imam Syafii ${ }^{*}$, Masayuki Ichinose ${ }^{2}$, Eiko Kumakura ${ }^{3}$, Steve Kardinal Jusuf ${ }^{4}$, \\ Wong Nyuk Hien ${ }^{5}$, Kohei Chigusa ${ }^{6}$, Yasunobu Ashie ${ }^{7}$ \\ ${ }^{1}$ Department of Architecture and Planning, Fakultas Teknik, Universitas Gadjah Mada, Jl. Grafika No. 2 \\ Kampus UGM, Yogyakarta 55281 \\ ${ }^{2}$ Graduate School of Urban Environmental Sciences, Department of Architecture and Building Engineering, \\ Tokyo Metropolitan University, 1-1 Minami-Osawa, Hachioji-shi, Tokyo, Japan 192-0397 \\ ${ }^{3}$ Urban Planning Division, Urban Planning Department, National Institute for Land and Infrastructure \\ Management, 1 Tachihara, Tsukuba City, Ibaraki Prefecture, Japan 305-0802 \\ ${ }^{4}$ Engineering, Singapore Institute of Technology, 10 Dover Drive, Singapore, 138683 \\ ${ }^{5}$ Department of the Built Environment, School of Design and Environment, National University of Singapore, \\ 4 Architecture Drive, \#03-04, Singapore 117566 \\ ${ }^{6}$ Shimizu Corporation, 3-5-7 Honmachi, Chuo-ku, Osaka 541-8520, Japan \\ ${ }^{7}$ Department of Environmental Engineering, Building Research Institute, 1 Tachihara, Tsukuba-shi, Ibaraki- \\ ken 305-0802, Japan
}

\begin{abstract}
Effective utilization of urban surface modification and landscaping through appropriate planning and design is becoming increasingly important. In contrast to the large number of studies on urban microclimates, few studies have directly focused on the outdoor thermal environment, in particular those investigating the role of water bodies. To optimize the usage of water bodies and to identify the distinguishing factors that may affect the benefits of cooling, a coupled computational fluid dynamics calculation and surface temperature calculation were used to estimate the cooling influence of water bodies on urban microclimates. The study presented in this paper simulated nine unique cases of a simplified urban neighborhood to evaluate the unique effect of different water pond configurations. In summary, within the urban canyon, the study results highlight the importance of a water body's configuration and positioning. Relative to prevailing winds, larger water pond surfaces tended to produce a better thermal environment, while equally distributed water ponds seemed to influence a wider area.
\end{abstract}

Keywords: Cooling effect; Numerical modeling; Thermal environment; Urban canyon; Water body

\section{Introduction}

Considerable variations in land usage, land cover, and urban surface texture in a city contribute to various urban problems, such as an urban heat island (UHI). UHI, where the urban area is warmer than the rural area, affects a building's energy consumption as well as the occupant's thermal comfort, health, and well-being (Brontowiyono et al., 2011; Wibowo and Salleh, 2018; Ibrahim et al., 2018). This generates interest among planners and designers in UHI mitigating strategies. Although still limited, research has been

*Corresponding author's email: nedyomukti@ugm.ac.id, Tel.: +62-82229990620 doi: 10.14716/ijtech.v12i3.4126 
conducted on a water body's ability to ameliorate a warm urban microclimate. Generally, these studies have shown that the air temperature is $1-5^{\circ} \mathrm{C}$ lower near water bodies (e.g., lakes, rivers, wetlands, and ponds) in comparison to adjacent built-up areas, particularly during the day (Jusuf et al., 2009; Völker et al., 2013; Lu et al., 2017; Jin et al., 2017; Syafii et al., 2017a; Cai et al., 2018; Jacobs et al., 2020). However, there is still a lack of design consideration in arranging effective water bodies to improve urban thermal environments. Therefore, further investigation is needed to verify the mitigating capacity of water bodies and to advance the current understanding of the influential factors that may be useful for planners and designers.

The present research, introduced numerical modeling for a comprehensive parametric study. The numerical model consists of the computational fluid dynamics (CFD) calculation and surface temperature calculation (Ca et al., 1999; Ashie and Kagiya, 2010; Ashie and Kono, 2011). Addressing the need to understand the effects and characteristics of water bodies in urban canyons to derive optimum design solutions and guidelines, the present study aimed to evaluate the thermal benefits of water bodies and to provide a better understanding of the various factors that influence the intensity of beneficial water body cooling, including the interactions among air temperature, humidity, wind flows, and the urban water body's morphology inside an urban canyon. To achieve these objectives, a parametric study was conducted to evaluate the thermal environment around an actual urban canyon (a simplified representation of an urban neighborhood), which had been affected by the configurations of various water bodies. The generic form provides a useful prognostic tool for studying an urban microclimate within a relatively uniform area. It produces outcomes that are more manageable and easier to interpret than other techniques. Parametric studies have mostly focused on the air temperature change caused by the presence of water bodies in urban canyons and the factors influencing the change. Thus, several methods were used to evaluate the effect. First, a climatic map from the numerical result was used to assess how each case influenced the temperature of the study area of interest. The average temperature changes over the entire study area of interest were also evaluated, providing a rough estimate of how a particular case influenced the whole study area of interest. Lastly, an attempt was made to identify the most influential factor by assessing the cooling occurrence in each case in the study area of interest.

\section{Methods}

The present study employed a coupled CFD and surface temperature calculation. The simulation was basically steady-state, which used a Reynolds-averaged Navier-Stokes model and focused on the analysis of the time-averaged wind and thermal environment over a neighborhood scale area. The coupled numerical modeling procedure was composed of surface temperature and fluid flow calculations (CFD). Basically, the surface temperature computation calculated the unsteady three-dimensional (3D) temperature distribution using input data from the building model, building thermal structure, and type of surface material. The CFD calculation was based on equations that consider the compressibility and correlation of density variations using the Favre average (density-weighted average, massweighted average). Moreover, the standard K-epsilon $(\mathrm{k}-\varepsilon)$ turbulence model was used for the turbulence model approximations. Providing a more detailed calculation of each equation presented here is beyond the scope of the present study. However, for additional information on the calculation of the CFD and surface temperature, please refer to the research by Ashie and Kagiya (2010) and Ca et al. (1999). 


\subsection{Assessment of the Influence of Urban Water Bodies}

To achieve the objectives of the study, nine cases were evaluated using coupled numerical modeling. These cases represented the conditions of urban canyons exposed to various factors related to the water body's physical properties. All the cases are shown in Table 1. A summary of the model for the parametric study is shown in Figure 1.

Table 1 Cases for the parametric study

\begin{tabular}{|c|c|c|c|c|c|c|c|c|c|}
\hline \multirow{2}{*}{ Treatment } & \multicolumn{9}{|c|}{ Cases } \\
\hline & 1 & 2 & 3 & 4 & 5 & 6 & 7 & 8 & 9 \\
\hline All water & $\sqrt{ }$ & & & & & & $\sqrt{ }$ & & \\
\hline No water & & $\sqrt{ }$ & & & & & & & \\
\hline Big EQD & & & $\sqrt{ }$ & & & & & $\sqrt{ }$ & \\
\hline Big C & & & & $\sqrt{ }$ & & & & & \\
\hline Small EQD & & & & & $\sqrt{ }$ & & & & $\sqrt{ }$ \\
\hline Small C & & & & & & $\sqrt{ }$ & & & \\
\hline Measured water $\left(37^{\circ} \mathrm{C}\right)$ & $\sqrt{ }$ & & $\sqrt{ }$ & $\sqrt{ }$ & $\sqrt{ }$ & $\sqrt{ }$ & & & \\
\hline Chilled water $\left(15^{\circ} \mathrm{C}\right)$ & & & & & & & $\sqrt{ }$ & $\sqrt{ }$ & $\sqrt{ }$ \\
\hline
\end{tabular}

Figure 1 shows the configurations of the water ponds for each case, which consisted of big ponds with equally-distributed configurations (Big EQD), big ponds with centered configurations (Big C), small ponds with equally-distributed configurations (Small EQD), and small ponds with centered configurations (Small C). Regarding the water surface area, the big pond cases covered 35\% of the ground surface inside the study area of interest, while the small pond cases covered $12.5 \%$.

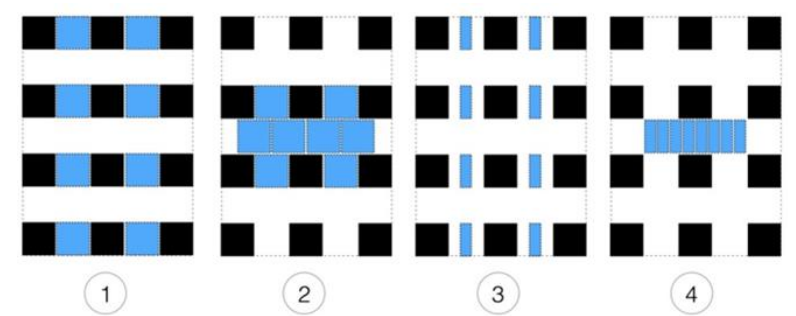

Figure 1 Model plan for the parametric study (1) big pond equally distributed (Big EQD), (2) big pond centered (Big C), (3) small pond equally distributed (Small EQD), (4) small pond centered (Small C)

\subsection{Computational Setting}

The computational domain and grid resolution of the present study was set with a total of 700,000 cells; the size of each cell is $1 \mathrm{~m}^{3}(1 \mathrm{~m} \mathrm{x} 1 \mathrm{~m} \mathrm{x} 1 \mathrm{~m})$. Inside the domain, an array of building blocks representing an idealized neighborhood with a uniform surrounding environment and a 2-story detached house was modeled. Moreover, as suggested by the CFD best practice guideline, the area of interest in the studies was roughly positioned at the center-end of the model, relative to the prevailing wind (Figure 2). Therefore, some spaces outside the study area of interest acted as an obstacle to the prevailing wind and represented airflow in the urban area.

To obtain the boundary values of the model computational domain, data from the field measurement at an outdoor scale model (Syafii et al., 2017a) were used. The data were readily available and generally represented a typical hot day in Japan, characterized by high air temperature and relatively dry and calm airflow. For this numerical study, the collected weather data from the field measurements on the August 5, 2015 were chosen, 
representing a typical clear day (Figure 3). Regarding the surface properties, the relevant parameters and values were taken from Ichinose et al. (1999) and Ihara et al. (2003). A summary of the surface properties is shown in Table 2.

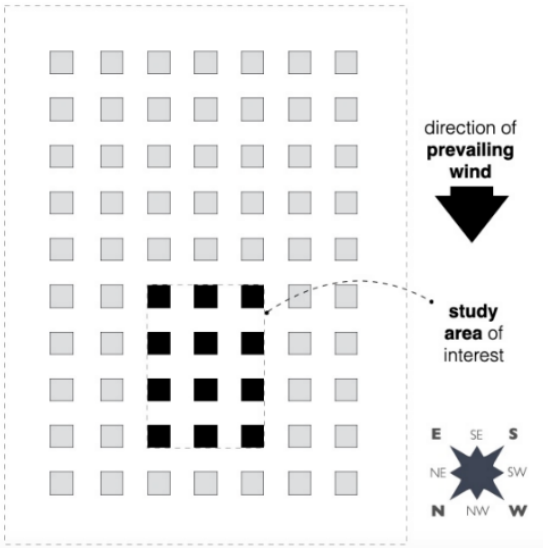

Figure 2 Numerical domain for the parametric study

Particularly for water temperature, the numerical modeling treated the water temperatureas the input values. Similar to the weather input, the water temperature for those cases with natural water conditions was given as the measured data from the field measurement. Furthermore, the boundary conditions for the CFD model were set according to research by Ashie and Kono (2011).
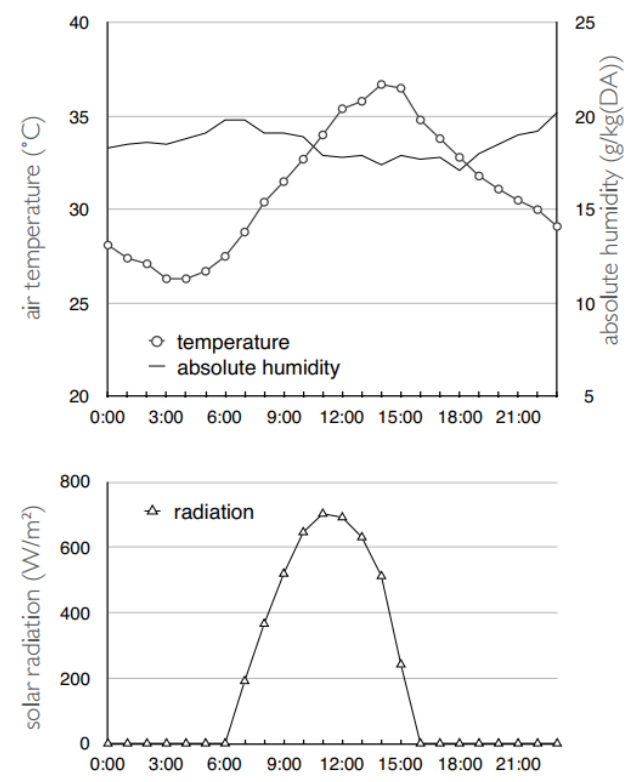

Figure 3 Hourly average of air temperature $\left(T_{a}\right)$, absolute humidity $(A H)$, and solar radiation recorded on August 5, 2015 (Syafii et al., 2017a)

Table 2 Values of the surface properties

\begin{tabular}{lcc}
\hline \multicolumn{1}{c}{ Surface Properties } & $\begin{array}{c}\text { Concrete (building } \\
\text { and pavement) }\end{array}$ & Water \\
\hline Albedo (-) & 0.18 & 0.08 \\
Surface emissivity (-) & 0.96 & 0.93 \\
Evaporation efficiency (-) & 0.05 & 1.00 \\
Density $\left(\mathrm{kg} \mathrm{m}^{-3}\right)$ & $2.4 \times 10^{3}$ & $1.0 \times 10^{3}$ \\
Specific heat $\left(\mathrm{J} \mathrm{kg}^{-1} \mathrm{~K}^{-1}\right)$ & 882 & 4200 \\
\hline
\end{tabular}




\section{Results}

This section summarizes the results of the parametric study. For the main analysis and discussion, the data were conditionally sampled for 12:00 pm (daytime). That particular time of day is generally the hottest, with the sun angle at its highest position. The results are discussed relative to human height. However, due to the limitation of the size and configuration of the cell from the numerical modeling (the size of the cell was $1 \mathrm{~m}^{2}$ ), the results are extracted from a $2 \mathrm{~m}$ height, slightly higher than the average human height.

\subsection{Examination of the Effect of Different Pond Configurations}

Figure 4 illustrates the effect of different water pond sizes on the distribution of air temperature. The first two water pond configurations (Big EQD and Small EQD) were compared to dry, no-pond conditions (see Figure 1). Although it was relatively limited, the different water pond sizes had a noticeable effect on the distribution of air temperature. Generally, a larger water pond tended to generate lower air temperatures and to spread its cooling effect toward a broader area. Nevertheless, in comparison to the no-water condition (Figure 4, no. 3), both EQD pond conditions showed the ability to lower the air temperature effectively, particularly at the downwind area and around the building gaps.

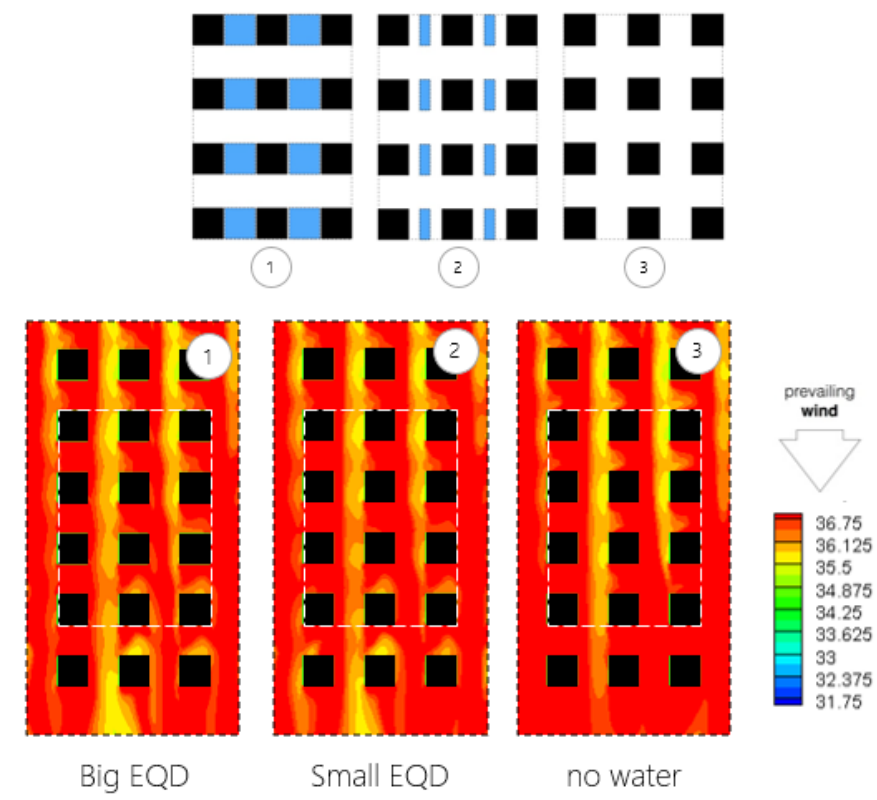

Figure 4 Horizontal distribution of air temperature for different pond configurations: (1) Big EQDCase 3; (2) Small EQD-Case 5; (3) no water or all concrete-Case 2

Figure 5 shows the distribution of air temperature due to different water pond configurations: Big EDQ and Small EDQ, Big C and Small C (Case 3-Case 6, refer to Figure 1). The air temperatures around the ponds with Big $C$ configuration (no. 2, Case 4) were found to be the lower than the temperatures around the other configurations. However, the cooling effect seemed prominent only in the middle of the study area of interest where the water pond was located. In contrast, the Big EQD water pond tended to have a more spreadout cooling effect. The lower air temperature was shown to almost cover the entire study area of interest. Although the existence of cooler air was less prominent, the same tendency was also shown in the smaller pond configuration of both types (EQD and C). 


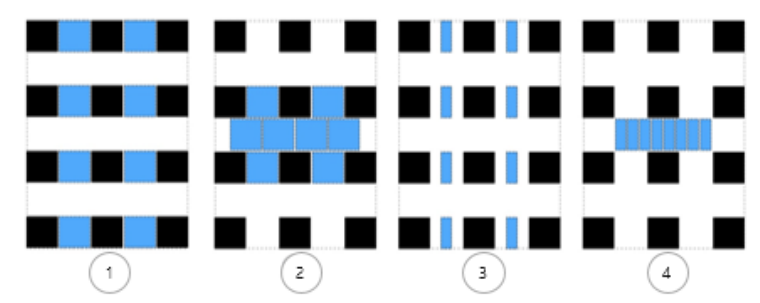

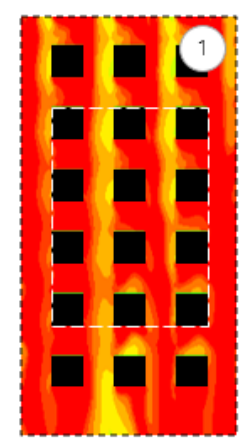

Big EQD

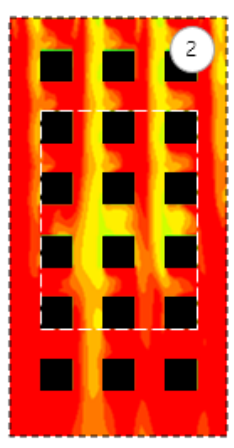

Big C

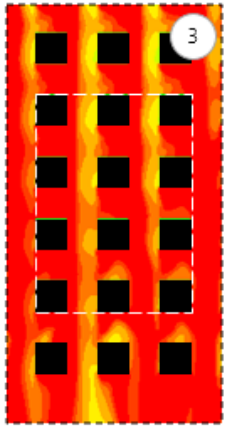

Small EQD

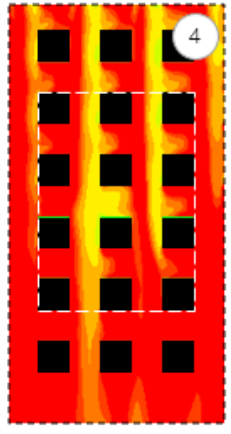

Small C

Figure 5 Horizontal distribution of air temperature for the different water pond configurations: (1) Big EDQ-Case 3; (2) Big C-Case 4; (3) Small EDQ-Case 5; (4) Small C-Case 6

\subsection{Examination of the Effect of Different Water Temperatures}

The introduction of water ponds with chilled water showed the potential to further cool the air temperature, as found by Theeuwes et al. (2013) and Syafii et al. (2017b). Therefore, to advance the design effectiveness of the chilled water pond, three water pond configurations were assessed with the inclusion of chilled water.

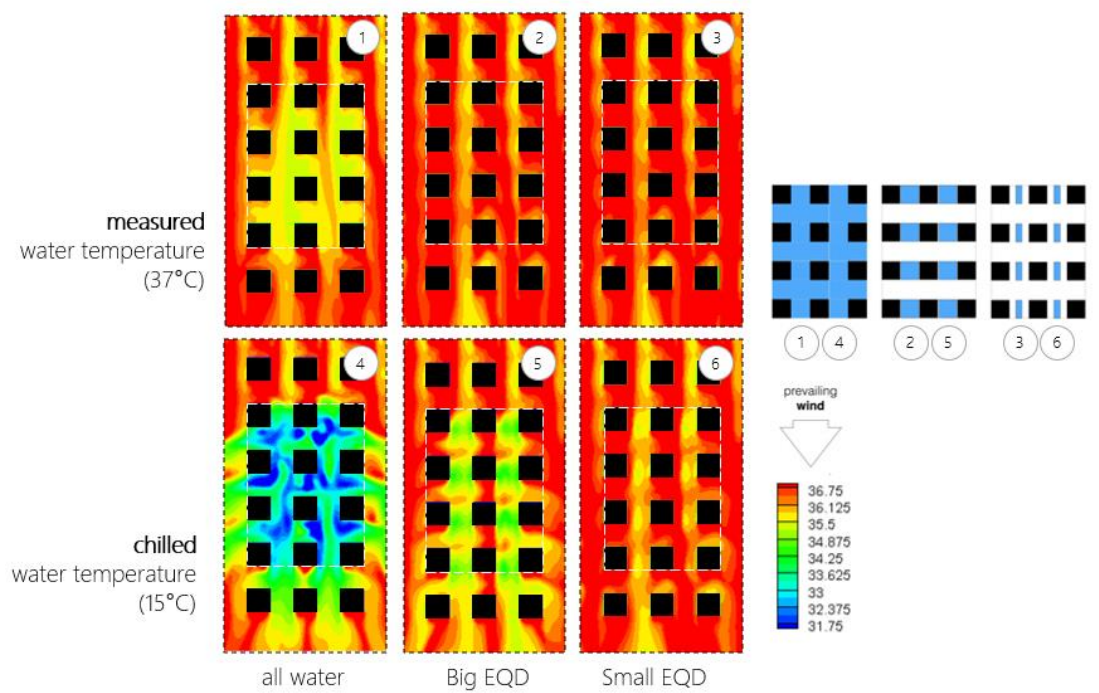

Figure 6 Horizontal distribution of air temperatures for different water pond configurations with different water temperatures: (1 and 3) all water configurations, (2 and 4) Big EQD configurations, (3 and 6) Small EQD configurations

Figure 6 shows the air temperature distribution of both types (EQD and C) of big pond and small pond configurations, one with a measured water temperature $\left(37^{\circ} \mathrm{C}\right)$ and the others set to $15^{\circ} \mathrm{C}$. Overall, the introduction of chilled water into the pond was able to further cool the air. The cooling effect was found to increase significantly as the size of the pond increased. The impact of the cooling improvement could also be seen beyond the study area of interest. Even in the small pond configuration of both typse (EQD and C), the 
cooling improvement with chilled water seemed to exceed that of the big pond configuration of both typse (EQD and C) with non-chilled water. This result may generate new solutions for increasing the benefits of cooling the water when there are space limitations in urban areas for water bodies.

\section{Discussion}

The air temperature distribution maps, which were developed from the numerical modeling, suggest that some factors influence the distribution of air temperature more than others. To quantify the temperature change caused by these influential factors, all of the cases were evaluated based on the calculated air temperature $\left(T_{a}\right)$, as shown in Figure 7. The boxplot shows the calculated $T_{a}$ value over the entire study area of interest, with error bars indicating its variability. Interestingly, the EQD water ponds seemed to generate a lower $T_{a}$ in comparison to the centered water ponds. These trends were seen in both types of ponds, although the bigger ponds showed slightly better thermal conditions than the smaller ponds. The lowest $T_{a}$ was found with the chilled water conditions, particularly if the water area was larger. Cases with chilled water seemed able to generate a lower $T_{a}$.

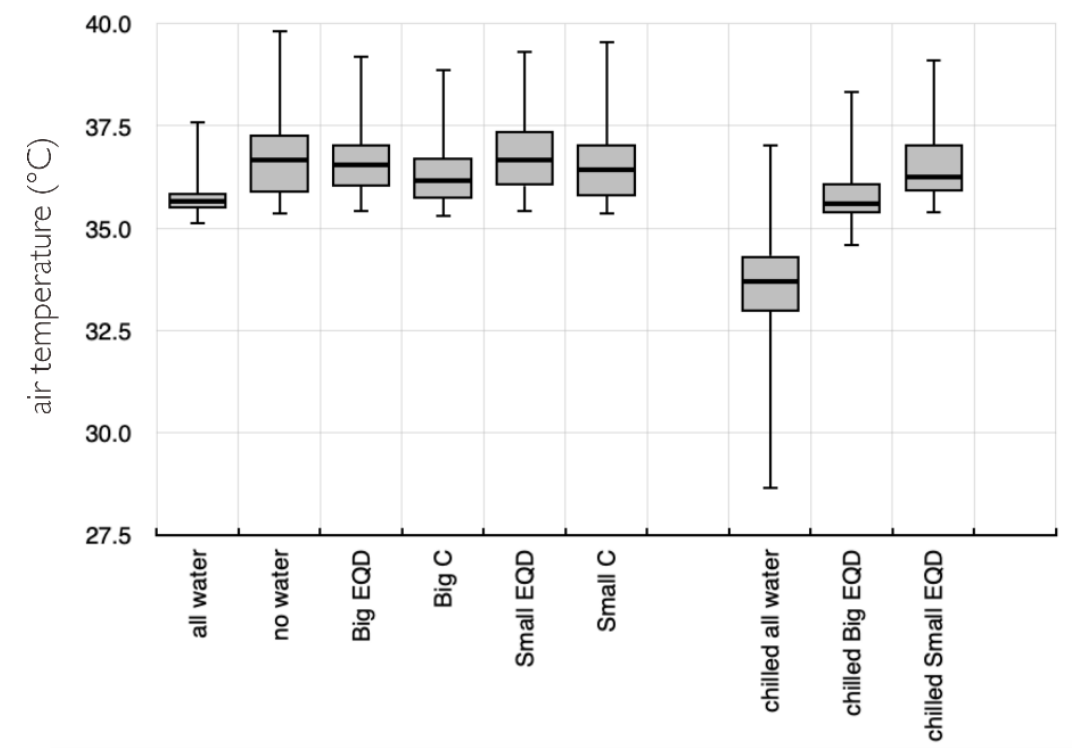

Figure 7 Average air temperature over the study area of interest for all cases

Generally, these temperature changes show the approximate impact of size and water temperature on the overall air temperature condition. For further analysis, an attempt was made to deepen our understanding of these influential factors by assessing the occurrence of cooler air. The occurrence of cooler air in each case was evaluated and compared to determine the correlation between the water body's potential benefits and the influential factors. Using a simple mathematical calculation, the occurrence of cooler air $\left(\Delta T_{c}\right)$ was derived from the difference in the air temperature of a particular factor for each case, (i.e., pond size, pond configuration, and water temperature) with a no-water condition as a reference. For that particular point, $\Delta T_{c}$ in the study area of interest was calculated as follows:

$$
\Delta T_{c}=T_{c}-T_{c 2}
$$

where $T_{c}$ is the air temperature calculated from cases with a water pond and $T_{c 2}$ is the air temperature calculated from cases with a no-water pond. This measure could give a general overview of the cooling effect intensity and its influential factors relative to the water pond 
configuration within the urban canyon. For analysis purposes, the occurrence of cooler air for all-water cases, big ponds and small ponds, were plotted in relation to air temperature (Figure 8) taken from the no-water case. Moreover, $T_{c}$ and $T_{c 2}$ were extracted from the same height, the same point position, at the same time.
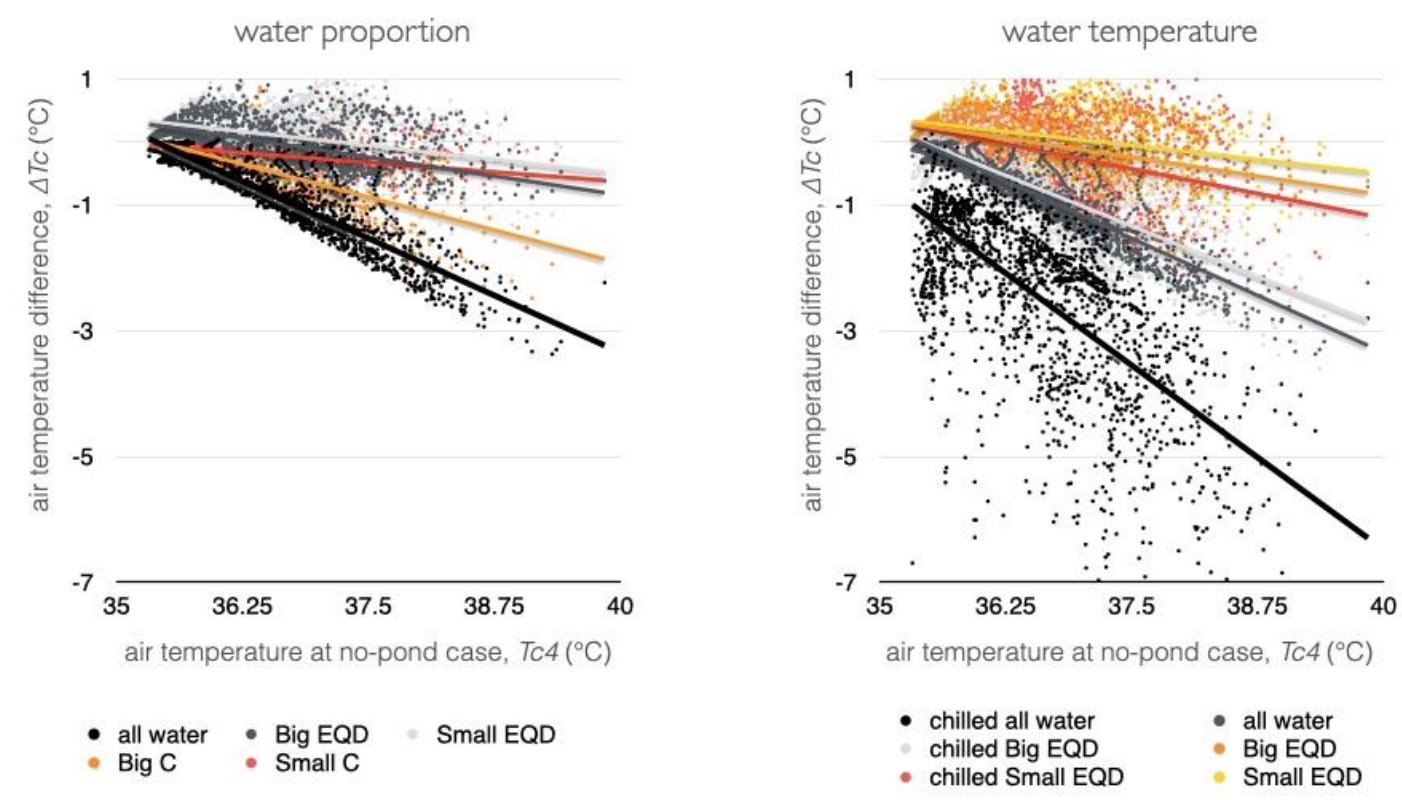

Figure 8 Comparison of the occurrence of cooler air temperature for all water (big ponds and small ponds) with various configurations (left), and in cases with the introduction of chilled water (right) relative to the no-pond air temperature condition

The centered pond configurations seemed to have a greater cooling effect than the EQD configurations (Figure 8-left). This was possibly due to the fact that the accumulation of more water in the centered area created a greater cooling effect, although both configurations had the same surface water areas. However, as found earlier, the EQD pond configuration seemed to have an effect on larger areas, which potentially could have a greater impact. It is also considered to be more suitable for an urban area with limited space. While larger water ponds generate a greater amount of cool air, with the introduction of chilled water (in this case, $15^{\circ} \mathrm{C}$ ), the cooling benefits were significantly improved (Figure 8-right). Thermal capacity change in the chilled water case seemed to generate a greater amount of cool air while resulting in the greatest temperature reduction. Additionally, by looking at each pond case, it can be generalized that the incremental benefits of cases with chilled water seemed to correlate with the increase in the surface area. A larger water area meant a greater reduction in air temperature, which also meant that a greater amount of cooler air was generated. Additionally, by looking at the trend line inclination, the air temperature reductions most likely occurred at higher air temperatures and under drier conditions. These tendencies were more apparent in ponds with larger water surface areas and those with chilled water.

Further analysis showed a good correlation between the size of the water pond and its ability to reduce the air temperature (Figure 9). The figure describes the relationship between the average of the air temperature difference (relative to the no-water pond condition), $\Delta T_{c}$, and the water surface ratio (WSR), which is the ratio of the total surface water area $\left(A_{w}\right)$ relative to the total unbuilt surface area in the study area of interest $\left(\mathrm{AT}_{\mathrm{T}}\right)$, with the diameter of the circle defined as the total area where the cooler air occurred. The 
total area of cooler air illustrates the sum of the cells that had a lower air temperature relative to the reference case (no-water case).

$$
\text { WSR }=\mathrm{Aw} / \mathrm{A}_{\mathrm{T}}
$$

Generally, the decrease in the air temperature changed as the water surface area increased, as found earlier (Figure 9-left). Additionally, in terms of the water pond configuration, all the cases with a centered configuration seemed to have a similar number of cells with cool air (similar size of circle). However, the EQD configurations showed an increase in the number of cells with cool air as the water surface area increased. This result may suggest that quantitatively centered configurations might provide a greater amount of cool air while having a lower reduction in air temperature in comparison to the EQD configurations. Furthermore, with the addition of chilled water, the increase in surface area seemed to further enhance the cooling benefits of the water pond (Figure 9-right). Cooler air and a decrease in the air temperature were clearly visible with the introduction of cool water.

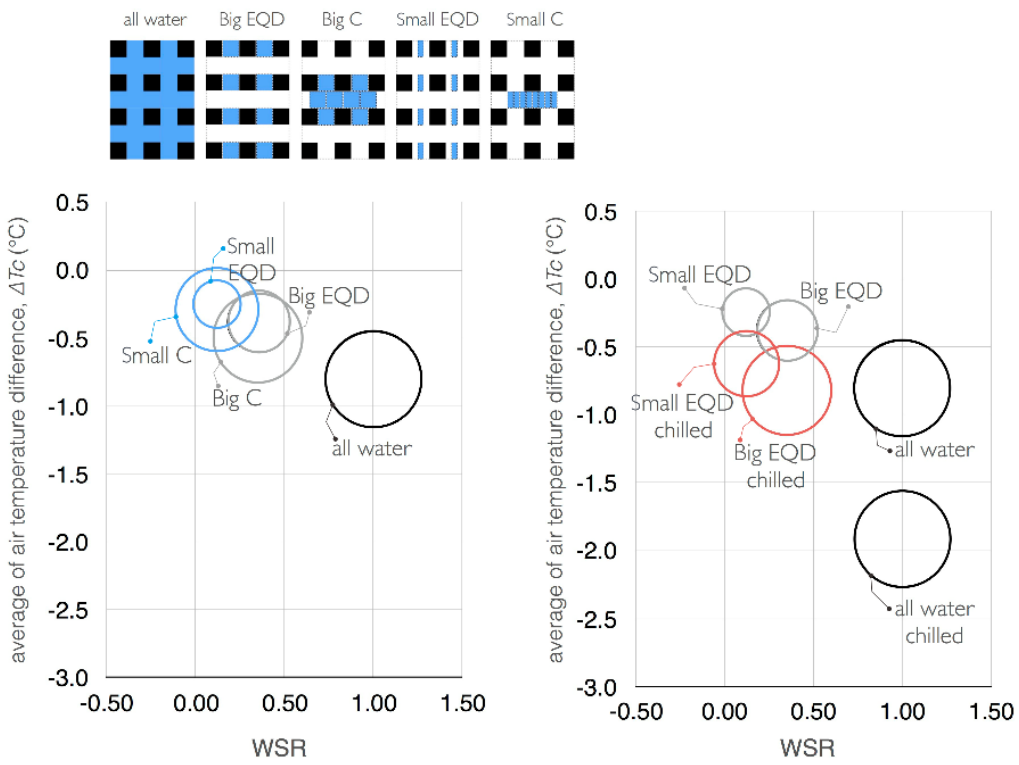

Figure 9 Correlation of air temperature reduction with water surface area ratio (AW/AT) and the occurrence of cooler air

\section{Conclusions}

This paper presented the results from a parametric study with a hypothetically urban neighborhood in which the water surface area, spatial configuration, and water temperature were varied. Most of the factors affecting cooling of air temperature (pond sizes, arrangements, and thermal capacity) were considered. Coupled numerical modeling, surface temperature calculation, and CFD calculation were used to obtain a better understanding of the effects of these influential factors and to determine the most effective design consideration for a water body's application inside the urban canyon, where buildings and other urban elements might influence a pond's microclimate benefits. Parametric studies using numerical simulation have the advantage of allowing a broad sample of urban surface modifications to be analyzed and compared, thanks to the rapid development of computational technology.

The results show that the air temperature is lower near water bodies than near a hard surface (concrete). The water body's ability to reduce the air temperature can be seen as a 
positive indicator for achieving enhanced thermal environments. Furthermore, the cooling effect of water bodies in urban canyons is influenced by, and depends on, the size and distribution of the water bodies with respect to wind speed and direction. Generally, with the same water surface area, the cases with EQD configurations were able to influence a much larger area of the canyon while the cases with centered configurations tended to generate a greater amount of cool air. Additionally, by keeping the water temperature low, the cooling intensity from the ponds increased significantly. The greatest effect from the chilled water pond occurred in the larger bodies of water.

However, the current study is limited to a simplified urban residential microclimate. Due to the complexity of the urban structure, surface materials, and other factors, the study's conclusion may not be appropriate for higher-density urban city spaces. Thus, potential future research on the cooling impact of water bodies could include factors, such as the influence of other types of water bodies (e.g., flowing water, water spray, water wall, etc.) in combination with other surface modifications (e.g., trees, shading devices, etc.), a more detailed water bodies form factor, or even exposure to a different predominant microclimate. Furthermore, the current study demonstrates the possibility of enhancing the cooling benefits of water bodies by introducing chilled water, which needs further investigation.

\section{References}

Ashie, Y., Kono, T., 2011. Urban-scale CFD Analysis in Support of a Climate-sensitive Design for the Tokyo Bay Area. International Journal of Climatology, Volume 31(2), pp. 174188

Ashie, Y., Kagiya, K., 2010. High Resolution Numerical Simulation on the Urban Heat Island of the Entire 2 Wards of Tokyo using Earth Simulator. Technical note of National Institute for Land and Infrastructure Management no. 583, National Institute for Land and Infrastructure Management, Ministry of Land, Infrastructure, Transport and Tourism, Tsukuba City, Ibaraki Prefecture, Japan

Brontowiyono, W., Lupiyanto, R., Wijaya, D., Hamidin, J., 2011. Urban Heat Islands Mitigation by Green Open Space (GOS) Canopy Improvement: A Case of Yogyakarta Urban Area (YUA), Indonesia. International Journal of Technology, Volume 2(3), pp. 207-214

Ca, V.T., Asaeda, T., Ashie, Y., 1999. Development of a Numerical Model for the Evaluation of the Urban Thermal Environment. Journal of Wind Engineering and Industrial Aerodynamics, Volume 81(1-3), pp. 181-196

Cai, Z., Han, G., Chen, M., 2018. Do Water Bodies Play an Important Role in the Relationship between Urban Form and Land Surface Temperature? Sustainable Cities and Society, Volume 39, pp. 487-498

Ibrahim, S.H., Ibrahim, N.I.A., Wahid, J., Goh, N.A., Koesmeri, D.R.A., Nawi, M.N.M., 2018. The Impact of Road Pavement on Urban Heat Island (UHI) Phenomenon. International Journal of Technology, Volume 9(8), pp. 1597-1608

Ichinose, T., Shimodozono, K. Hanaki, K., 1999. Impact of Anthropogenic Heat on Urban Climate in Tokyo. Atmospheric Environment, Volume 33(24-25), pp. 3897-3909

Ihara, T., Aida, H., Yoshida, Y., Handa, T., Matsuhashi, R., Ishitani, H., 2003. Evaluation of $\mathrm{CO}_{2}$ Emissions Reduction Effect from the Building by Introducing High Light-reflective and High Heat-emissive Paint Considering Urban Thermal Environment. In: Proceedings of the 19th Conference on Energy, Economy, and Environment, Tokyo, Japan, pp. 655-660

Jacobs, C., Klok, L., Bruse, M., Cortesão, J., Lenzholzer, S., Kluck, J., 2020. Are Urban Water Bodies Really Cooling? Urban Climate, Volume 32, pp. 1-14 
Jin, H., Shao, T., Zhang, R., 2017. Effect of Water Body Forms on Microclimate of Residential District. Energy Procedia, Volume 134, pp. 256-265

Jusuf, S.K., Wong, N.H., Syafii, N.I., 2009. Influence of Water Feature on Temperature Condition Hot Humid Climate. In: iNTA-SEGA 2009-Bridging Innovation, Technology and Tradition, Thailand

Lu, J., Li, Q., Zeng, L., Chen, J., Liu, G., Li, Y., Li, W., Huang, K., 2017. A Micro-climatic Study on Cooling Effect of an Urban Park in a Hot and Humid Climate. Sustainable Cities and Society, Volume 32, pp. 513-522

Syafii, N.I., Ichinose, M., Kumakura, E., Jusuf, S.K., Chigusa, K., Wong, N.H., 2017a. Thermal Environment Assessment around Bodies of Water in Urban Canyons: A Scale Model Study. Sustainable Cities and Society, Volume 34, pp. 79-89

Syafii, N.I., Ichinose, M., Kumakura, E., Jusuf, S.K., Chigusa, K., Wong, N.H., 2017b. Enhancing the Potential Cooling Benefits of Urban Water Bodies. Nakhara: Journal of Environmental Design and Planning, Volume 14, pp. 29-40

Theeuwes, N.E., Solcerova, A., Steeneveld, G.J., 2013. Modelling the Influence of Open Water Surfaces on the Summertime Temperature and Thermal Comfort in the City. Journal of Geophysical Research: Atmospheres, Volume 118, pp. 8881-8896

Völker, S., Baumeister, H., Claßen, T., Hornberg, C., Kistemann, T., 2013. Evidence for the Temperature-mitigating Capacity of Urban Blue Space: A Health Geographic Perspective. Erdkunde, Volume 67(4), pp. 355-371

Wibowo, A., Salleh, K.O., 2018. Land Cover Types and Their Effect on the Urban Heat Signature of University Campuses using Remote Sensing. International Journal of Technology, Volume 9(3), pp. 479-490 